Check for updates

Cite this: RSC Adv., 2018, 8, 11850

Received 21st February 2018

Accepted 12th March 2018

DOI: 10.1039/c8ra01570h

rsc.li/rsc-advances

\section{Introduction of stereocomplex crystallites of PLA for the solid and microcellular poly(lactide)/ poly(butylene adipate-co-terephthalate) blends $\uparrow$}

\author{
Xuetao Shi, (DD *a Jianbin Qin, ${ }^{a}$ Long Wang, ${ }^{a}$ Liucheng Ren, ${ }^{a}$ Fan Rong, ${ }^{a}$ Daiheng Li, \\ Ryan Wang ${ }^{\mathrm{b}}$ and Guangcheng Zhang ${ }^{\star a}$
}

Solid and microcellular poly(L-lactide)/poly(butylene adipate-co-terephthalate) (PLLA/PBAT) blends with or without poly(D-lactide) (PDLA) were prepared via melt blending and batch foaming process with supercritical carbon dioxide, respectively. The introduction of PDLA on the rheological properties, crystallization behavior and dynamic mechanical properties of the PLLA matrix were investigated. The formed PLA stereocomplex between PLLA and PDLA enhanced the storage modulus and complex viscosity of PLLA/PBAT blends efficiently. Interestingly, the addition of $5 \mathrm{wt} \%$ or $10 \mathrm{wt} \%$ PDLA in the PLLA/PBAT blends was unfavorable for the PLLA crystallization behavior. The potential reason can be scPLA crystallites acting as the physical crosslinking points, which constrained the molecular mobility of the PLLA matrix and even blocked the nucleating effect of PBAT domains. Both the enhanced melt strength and decreased crystallinity of the PLLA matrix are favorable for the cell nucleation and growth and the gas adsorption, respectively. The designed partially foaming of PLLA/PBAT with or without PDLA was carried out to investigate the foaming mechanism. The final cell morphology of PLLA/PBAT foams exhibited typical open-cell structure mainly attributed to the soft immiscible PBAT phase as separated domains. With further addition of PDLA in the PLLA/PBAT blends, the microcellular morphology exhibited decreased average cell size and increased cell density. The sc-PLA crystallites networks in the PLLA matrix acted as cell nucleating agents, which meanwhile resisted the force of cell growth and then prevented the cell collapse.

\section{Introduction}

Polylactide (PLA) has been the subject of much attention because of its outstanding performance in terms of high stiffness and strength, biodegradability, biocompatibility and thermal processability and is often seen as an alternative to traditional petrochemical plastic. ${ }^{1-4}$ PLA has been widely used not only in the areas of biomedical and pharmaceutical application but also in the commodity areas such as packaging application. Except the relative high cost, the further application of PLA in more fields is limited due to its intrinsic stiffness, low crystallization rate, low melt strength and narrow processing window. To overcome those drawbacks, PLA modifications including copolymerization, ${ }^{5}$ blending, ${ }^{6}$ stereocomplexation, ${ }^{7}$ plasticization $^{8}$ and composition with nanoparticles ${ }^{9}$ are widely studied in the literature. With the purpose to decrease the cost,

${ }^{a}$ Department of Applied Chemistry, School of Science, Northwestern Polytechnical University, Xi'an, China.E-mail: shixuetao@nwpu.edu.cn; zhangguc@nwpu.edu.cn ${ }^{b}$ Total Corbion PLA BV, Room 903-905, 9/F Hongkong Plaza, No.283 Huaihai (M) Road, Shanghai 200021, China

$\dagger$ Electronic supplementary information (ESI) available. See DOI: $10.1039 / \mathrm{c} 8 \mathrm{ra} 01570 \mathrm{~h}$
PLA foams ${ }^{10}$ are thought to be potential application meanwhile with enhanced toughness and to be alternative of traditional polystyrene foams. PLA foaming ${ }^{11-13}$ is also considering as another technique to increase PLA's properties especially crystallinity due to the strong plasticization of blowing agent and the extensional flow during the foaming expansion process.

However, the production of PLA foams with a uniform cell morphology using supercritical $\mathrm{CO}_{2}$ or $\mathrm{N}_{2}$ as the physical blowing agents is still quite challenging. This is mainly due to PLA's low melt strength. The recent research to overcome this drawback to facility PLA foaming process includes introducing chain extender ${ }^{14,15}$ for branching structure, changing the $L / D$ ratio configuration, ${ }^{16}$ varying PLA's molecular weight, ${ }^{17}$ compounding with different types of additives, ${ }^{18,19}$ blending with other polymers having a higher crystallization rate, ${ }^{20}$ and controlling the gas contents. ${ }^{21}$ For example, PLA foam morphology can be greatly controlled by adding second component into the PLA matrix, which leads to increasing of cell density because of the promoted cell nuclei. $\mathrm{ZhaO}^{22}$ studied the microcellular PLA/PHBV (polyhydroxybutyrate-valerate) blend with or without nanoclay and reported the addition of nanoclay decreased the average cell size and increased the cell density, which was related to the enhanced crystallinity of PHBV 
in the blend because of nanoclay as nucleating agents. Pilla ${ }^{23}$ prepared PLA/PBAT (poly(butylene adipate- $c$-terephthalate)) foam by microcellular extrusion process using $\mathrm{CO}_{2}$ and found that compatibilized PLA/PBAT showed reduced the average cell size and volume expansion. $\mathrm{Yu}^{24}$ reported the open cell structure of PLA based on poly(butylenes succinate) (PBS) foams via batch foaming method using supercritical carbon dioxide and the cell opening rate can be around $97 \%$ with certain PBS content and foaming temperature. Our former research ${ }^{25}$ on the microcellular PLA/PBAT foams indicated the second phase PBAT had great influence on the final cell morphology with uniform cell distribution due to formed interface between PLA and PBAT phases. Even those PLA blends with different polymer can exhibit reduced cell size and increasing cell density. However, the rheological properties of PLA blends with other biodegradable polymers reported in the literature were not improved efficiently. ${ }^{26,27}$

Other modifications either with long chain branching structure or with inorganic nanoparticles to PLA foams can be summarized to enhance the PLA matrix strength and to facility the PLA foaming process. Li et $a l .^{28}$ reported the PLA foaming process was greatly facilitated by the introduction of a long-chain branching structure through reactive extrusion, which was mainly due to the increasing PLA strength and higher crystal nucleation potential. The incorporation of nanoclay ${ }^{19,29}$ into the PLA matrix is usually applied to improve or modify the modulus, melt strength, gas barrier performance of the final nanocomposites.

On the other hand, the crystallization behavior especially the crystallites and their related size seems another important parameter to affect the PLA foaming process and thus the cell morphology and final foam properties. It is also well known in literature that PLA is a chiral polymer with two enantiomers, poly(L-lactide) PLLA and poly(D-lactide) PDLA. The PLA stereocomplex crystals (sc-PLA) can be generated by the solution or melting blending between PLLA and PDLA. The sc-PLA shows great enhanced properties such as the thermal stability, fast crystallization rate, higher melting temperature and enhanced mechanical properties. It is generally accepted that those improvements are related the intermolecular interaction ${ }^{30}$ between L-lactyl unit chains and D-lactyl unit chains. Yamane and coworkers ${ }^{31}$ analyzed the crystallization behavior of PLLA with PDLA as a nucleating agent, which formed a large stereocomplex crystalline and effectively increased the number of PLLA spherulites and then the overall crystallization rate. Nouri and coworkers ${ }^{32}$ reported a greater improvement in PLA melt rheological properties for blends containing stereocomplex structures as the physical cross-links between PLLA and PDLA.

In this work, different amount of PDLA were introduced in the PLLA/PBAT blends by the melt blending and then compression molding processes. The influence of formed scPLA crystallites on the rheological properties, crystallization behavior and dynamic mechanical properties of the ternary PLLA/PBAT/PDLA blends were investigated. Then the PLLA/ PBAT-based blends were further foamed using supercritical $\mathrm{CO}_{2}$ as blowing agent via the solid batch foaming process. The effect of sc-PLA crystallites on the gas adsorption and diffusion behavior, and mainly on the cell morphology are also discussed. This work provided the enhanced melt strength of PLLA matrix with sc-PLA crystallites and therefore the tunable foaming morphologies, which could widen PLA foaming processing window without the cost of its biodegradability.

\section{Experiment}

\section{Materials}

The PLLA (Luminy L175) and PDLA (Luminy D070) used in this study was supplied from Total Corbion PLA BV(Gorinchem, Netherlands). The density of both PLLA and PDLA is $1.24 \mathrm{~g} \mathrm{~cm}^{-3}$, while the melt flow index for PLLA and PDLA are 3 $\mathrm{g} / 10 \mathrm{~min}\left(190{ }^{\circ} \mathrm{C} / 2.16 \mathrm{~kg}\right)$ and $20 \mathrm{~g} / 10 \mathrm{~min}\left(190{ }^{\circ} \mathrm{C} / 0.325 \mathrm{~kg}\right)$, respectively. PBAT was supplied by BASF under the trade mark of Ecoflex (density: $1.25-1.27 \mathrm{~g} \mathrm{~cm}^{-3}$; melt viscosity: $2.5-4.5 \mathrm{ml} /$ $10 \mathrm{~min}$ at $190{ }^{\circ} \mathrm{C}$; and melt temperature: $110-120^{\circ} \mathrm{C}$ ).

\section{Preparation of PLLA blends}

Both PLLA, PDLA, PBAT pellets were treated in the vacuum over at $65^{\circ} \mathrm{C}$ for at least 24 hours before the compounding process. A twin-screw extruder (SHJ-95, Lantai Plastics Machinery Co., Ltd., Lanzhou, China), with a screw diameter of $21.6 \mathrm{~mm}$ and $L /$ $D$ ratio of 40 , was used for PLA/PBAT-based blends. The melt compounding temperature of the barrel was in the range from 180 to $195{ }^{\circ} \mathrm{C}$, with the screw speed of $80 \mathrm{rpm}$. The strand extrudate was cut into pellets. The prepared PLLA/PBAT binary and PLLA/PBAT/PDLA ternary blends were then compressed in mold at $190{ }^{\circ} \mathrm{C}$ into sheets with a thickness of $0.5 \mathrm{~mm}$ for the foam processing. Table 1 records the samples list with different composition of PBAT and PDLA in the PLLA matrix.

\section{$\mathrm{CO}_{2}$ saturation and batch foaming}

The gas saturation experiments for PLLA-based sheets were carried out in high pressure vessel at $15 \mathrm{MPa}$ at $45^{\circ} \mathrm{C}$. The high purity $\mathrm{CO}_{2}$ was delivered to the autoclave by a supercritical fluid pump (SSI, S10SNXP1) from the $\mathrm{CO}_{2}$ cylinder. After saturated for 8 hours, the samples were removed from the high-pressure vessel and weighed on a balance (AUW120D, sensitivity 0.01 $\mathrm{mg}$ ) to measure gas uptake.

For desorption experiment, the PLLA/PBAT-based samples were allowed to desorb at room temperature under atmospheric pressure. Periodic mass measurements were conducted to record the amount of gas dissolved in the sample.

Table 1 Composition of PLLA/PBAT based blends with or without PDLA

\begin{tabular}{llll}
\hline Sample name & PLLA & PBAT & PDLA \\
\hline PLLA & 100 & 0 & 0 \\
PLLA/PBAT 9/1 & 90 & 10 & 0 \\
PLLA/PBAT 9/1 + 5\% PDLA & 90 & 10 & 5 \\
PLLA/PBAT 9/1+10\% PDLA & 90 & 10 & 10 \\
PLLA/PBAT 8/2 & 80 & 20 & \\
PLLA/PBAT 8/2 + 5\% PDLA & 80 & 20 & 5 \\
PLLA/PBAT 8/2+ 10\% PDLA & 80 & 20 & 10 \\
PLLA/PBAT 7/3 & 70 & 30 & \\
PLLA/PBAT 5/5 & 50 & 50 & \\
& &
\end{tabular}


The saturated specimens were transferred within $1 \mathrm{~min}$ to the silicon oil bath maintained at the prescribed foaming temperatures for certain time to generate the microcellular foams, followed by quickly quenching the foams in cold water.

\section{Characterization}

Rheological measurements were performed on a straincontrolled rheometer MCR 302 (Anton Paar, Austria) with a parallel plate geometry (diameter: $25 \mathrm{~mm}$ ) and a gap size of 1 $\mathrm{mm}$. Oscillatory frequency sweeps were carried out from 1 to $100 \mathrm{rad} \mathrm{s}^{-1}$ at $190{ }^{\circ} \mathrm{C}$ with a strain of $1 \%$ (in the linear viscoelastic region) for PLLA and its blends.

A differential scanning calorimeter (DSC1, Mettler Toledo, Switzerland) was used to study the crystallization behavior of PLLA and its blends. The weight of the samples was approximately $5 \mathrm{mg}$. All samples were placed in a hermetically sealed aluminum pan under a $50 \mathrm{ml} \mathrm{min}^{-1}$ nitrogen flow. The samples were firstly heated from $20{ }^{\circ} \mathrm{C}$ to $190{ }^{\circ} \mathrm{C}$ or $250{ }^{\circ} \mathrm{C}$ for samples with or without PDLA, respectively. All samples were kept isothermal for $5 \mathrm{~min}$ to remove any thermal history. The ramp rate for thermal program was $10{ }^{\circ} \mathrm{C} \mathrm{min}{ }^{-1}$. The glass transition temperature $\left(T_{\mathrm{g}}\right)$, cold crystallization temperature $\left(T_{\mathrm{c}}\right)$, enthalpy of cold crystallization $\left(\Delta H_{\mathrm{c}}\right)$ and apparent melting enthalpy $\left(\Delta H_{\mathrm{f}}\right)$ were determined from the DSC curves.

The crystallinity of the PLLA phase was calculated by

$$
\chi_{\mathrm{c}}(\% \text { crystallinity })=\frac{\Delta H_{\mathrm{f}}-\Delta H_{\mathrm{c}}}{\Delta H^{0}\left(1-W_{\mathrm{f}}\right)} \times 100 \%
$$

where $\Delta H^{0}$ is the enthalpy of melting per gram of $100 \%$ crystallinity (perfect crystal) of PLA $\left(93.6 \mathrm{~J} \mathrm{~g}^{-1}\right),{ }^{33}$ and $W_{\mathrm{f}}$ is the weight fraction of PBAT in the PLLA/PBAT binary blends.

The dynamic mechanical properties of PLLA, PLLA/PBAT binary and PLLA/PBAT/PDLA ternary blends were studied by dynamic mechanical analysis (DMA) (TA Instruments, TA Q800). The sheets used for DMA analysis were cut into a dimension of $10 \times 0.5 \times 40 \mathrm{~mm}^{3}$ and vibrated in tension mode at a frequency of $1 \mathrm{~Hz}$. All the DMA tests were carried out from room temperature to $120{ }^{\circ} \mathrm{C}$ using a $2{ }^{\circ} \mathrm{C} \mathrm{min}^{-1}$ temperature ramp.

The solubility of $\mathrm{CO}_{2}$ in these PLA samples was measured by a weight loss method, in which the samples were set in the chamber, followed by the saturation process to make the carbon dioxide diffuse into the samples. Then, those samples were rapidly taken out and weighed.

PLLA/PBAT foams with or without PDLA were dipped in liquid nitrogen and then immediately fractured. The exposed surfaces were sputter coated with $\mathrm{Au} / \mathrm{Pd}$. The microcellular morphologies of the prepared foams were investigated by SEM technique (TESCAN (VEGA 3 LMH)). Image analysis on the SEM images was conducted using the software Image-Pro Plusto obtain the average cell size and cell density. The cell density $N_{\mathrm{f}}$, defined as the number of cells per cubic centimeter of the foam, was calculated using the following equation: ${ }^{34}$

$$
N_{\mathrm{f}}=\left[\frac{n M^{2}}{A}\right]^{3 / 2}
$$

where $n$ is the number of cells, $A$ is the area of the micrograph in $\mathrm{cm}^{2}$, and $M$ is the magnification factor.

\section{Results and discussion}

\section{Effect of stereocomplex crystallites on rheology behavior of PLLA/PBAT blends}

The viscosity of PLA is the dominating parameter for its foaming behavior. In this work, the rheology behavior of PLLA/PBAT blends with or without PDLA were measured at $190{ }^{\circ} \mathrm{C}$, which was lower than the melting temperature of PLA stereocomplex. Fig. 1(a) and (b) show the complex viscosity and storage modulus as a function of frequency for different PLLA blends, respectively. As shown in Fig. 1(a), the addition of PDLA have remarkable effect on complex viscosity of PLLA/PBAT blends. Pure PLLA shows long Newtonian plateau typical of polymers at low frequencies followed by its shear thinning response. The PLLA/PBAT binary blends with different PBAT concentration show the similar complex viscosities compared to that of pure
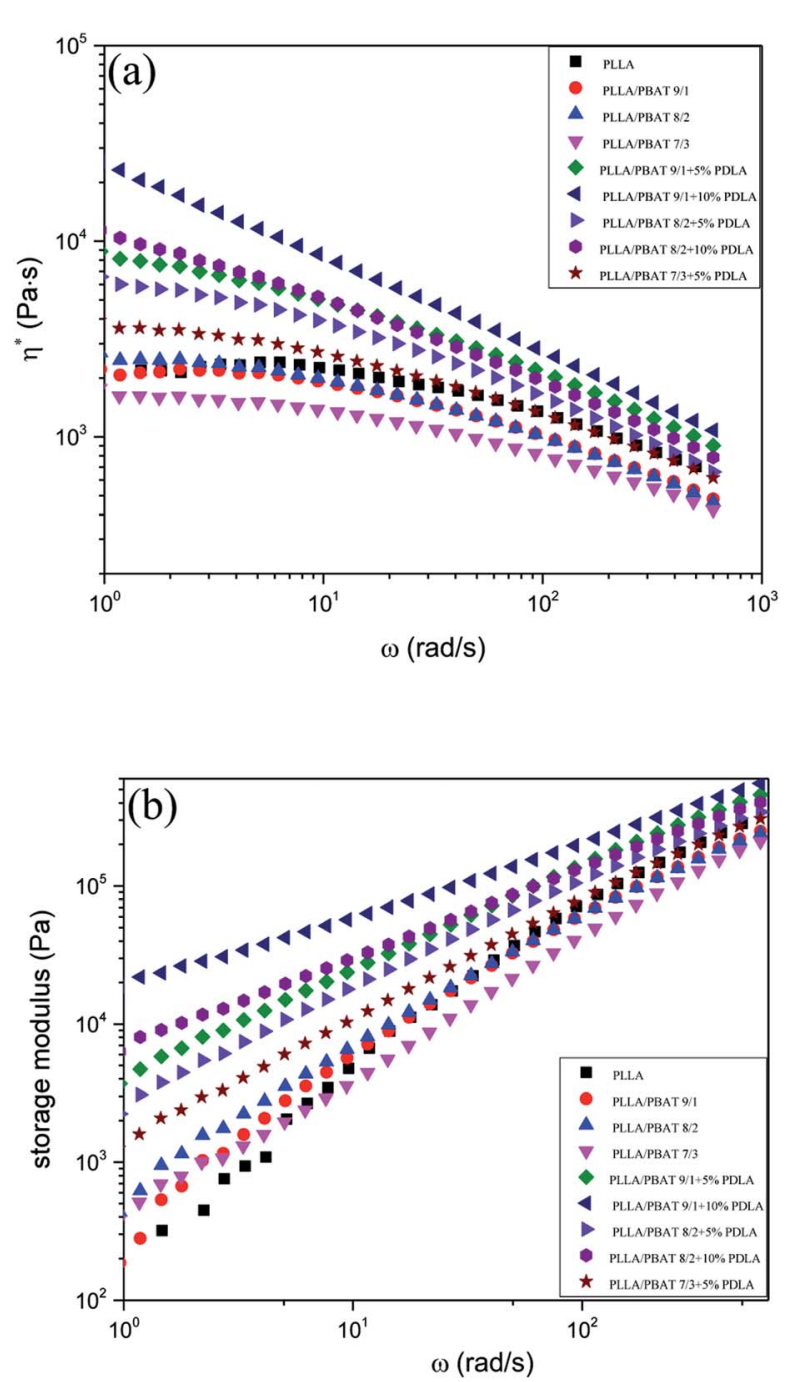

Fig. 1 Frequency dependences of (a) complex viscosity $\eta^{*}$ and (b) storage modulus $G^{\prime}$ of PLLA, PLLA/PBAT and PLLA/PBAT/PDLA at $190{ }^{\circ} \mathrm{C}$. 
PLLA, but shows slightly decreasing viscosity with the increasing of PBAT concentration from $10 \mathrm{wt} \%$, which is related to the lower complex viscosity of pure PBAT. Another difference is that the pure PLLA has a longer Newtonian plateau region than PLLA/PBAT blends. Meanwhile, PLLA/PBAT blends with 5 wt $\%$ PDLA or 10 wt $\%$ PDLA show much higher complex viscosities at low frequencies, which keep decreased with increasing frequency. Because the rheology measurements were carried out at $190{ }^{\circ} \mathrm{C}$, the addition of PDLA in the PLLA/PBAT blends would lead to the formation of PLA stereocomplex crystallites and the stereocomplex crystals remained in the system were contributed to the increase of viscosity. In literature, the inorganic nanoparticles ${ }^{22}$ or long-chain branching structure $^{28}$ were reported to be used to increase the PLA viscosity. Different from inorganic nanoparticles or chainextenders, the addition of PDLA in the PLLA/PBAT blends would result in a high level of interaction and strong entanglement between molecular chains as consequence of PLA stereocomplex formation and physical chain branching. In our former work, ${ }^{35}$ the influence of PDLA with different chemical structure and different concentration on the rheology of PLLA was studied systematically, and PDLA with certain concentration (5-10 wt\%) would greatly improve the melt strength of PLA.

Fig. 1(b) shows the frequency dependencies of the storage modulus $G^{\prime}$ of PLLA/PBAT blends and the related viscoelastic properties are discussed. The storage modulus $G^{\prime}$ provides a measure of blends stiffness and its frequency characterizes whether the material is in a liquid-like or solid-like state. PLLA/ PBAT blends without PDLA exhibit very similar rheological response as pure PLLA because the chains could be fully relaxed at $190{ }^{\circ} \mathrm{C}$, exhibiting the typical rheological response of a Newtonian liquid behavior with $G^{\prime} \sim \omega^{2}$ at low frequencies. However, PLLA/PBAT blends with $5 \%$ or $10 \%$ PDLA exhibited pronounced changes in rheological parameters. The $G^{\prime}$ (elasticity property) of PLLA/PBAT with PDLA exhibited a much slower frequency response, which can be confirmed by the smaller slope of the $G^{\prime}$ against the frequency. This pseudo-solidlike behavior reveals a relatively slow relaxation process and an increased elasticity of the blend melt. In literature, ${ }^{36,37}$ a transition from a Newtonian liquid to an Hookean solid is usually accompanied the formation of a mechanically stable network structure. In this work, the sc-crystallites reserved in the melt of PLLA/PBAT blends, which could act as cross-linking agents, are strongly related to the above rheological transition.

Another important concentration influence of PDLA and PBAT on the rheological properties can be concluded that the increasing of PBAT concentration is unfavorable for $G^{\prime}$, while the increasing of PDLA amount is favorable for $G^{\prime}$. Even at higher frequencies, the addition of more PDLA in the PLLA/ PBAT blends clearly enhances the $G^{\prime}$ of final blends. The effect of PDLA or the formed PLA stereocomplexs in the loss modulus $G^{\prime \prime}$ in Fig. S1 $\uparrow$ is also pronounced as in $G^{\prime}$. For example, the PLLA/PBAT 9/1 with 5\% PDLA presents a much higher $G^{\prime \prime}$ value than that of PLLA/PBAT 9/1 blends. Compared to pure PLLA, the incorporation of second incompatible PBAT phase decreases the value of $G^{\prime \prime}$, and $G^{\prime \prime}$ decreases with increasing PBAT concentration. While, the addition of PDLA in the PLLA/
PBAT blends increases the $G^{\prime \prime}$, which increases with more PDLA concentration.

The cross-over point of the curves of $G^{\prime}$ and $G^{\prime \prime}$ of PLLA/PBAT 9/1 and PLLA/PBAT 8/2 as the intersect with frequency is also recorded in Fig. $\mathrm{S} 2$ and $\mathrm{S} 3, \dagger$ respectively. This point is representative of the transition from viscous to elastic behavior. The binary PLLA/PBAT systems displays a single cross-over point at higher frequencies. With introduction of PDLA, both the $G^{\prime}$ and $G^{\prime \prime}$ increased, where $G^{\prime}$ increased significantly and $G^{\prime \prime}$ only slightly. Consequently, for the system with 5\% PDLA, the curves of $G^{\prime}$ and $G^{\prime \prime}$ intersected at a lower frequency. Interestingly, with further increase of $10 \%$ PDLA in PLLA/PBAT system, both curves merge and eventually it is can also be possible that $G^{\prime}$ is greater than $G^{\prime \prime}$ through all the frequency range. These result confirm the solid-like behavior for the ternary system, which was strongly related to the amount of PDLA concentration.

The much higher $G^{\prime}$ and complex viscosities indicates a transition from liquid-like to solid-like viscoelastic behavior for the PLLA/PBAT blends with PDLA as compared to PLLA/ PBAT blends. This behavior is characteristic of a network-like structure due to the reserved stereocomplex crystallites. The molecular interaction between PLLA and PDLA due to the strong inter-molecular hydrogen bonding can be the explanation to restrain the mobility of the PLLA matrix and therefore the chain relaxation of PLLA.

\section{Effect of PDLA on the crystallization behavior of PLLA/PBAT blends}

For PLA foaming, enhancing PLA's slow crystallization kinetics and then its crystallinity can be good method to improve its inherently low melt strength. However, higher crystallinity of PLLA matrix may also lead to some problems such as low gas adsorption concentration or non-uniform cell morphology of PLA foams. The addition of PDLA were already confirmed in literature for the formation of PLA stereocomplex crystallites, ${ }^{38,39}$ which could act as the nucleating agents for PLLA crystallization. Fig. 2(a), (b) and (c) show the DSC first heating, cooling and second heating thermograms of PLLA/PBAT blends with or without PDLA. In this work, the first heating scan related to the compress molding is also investigated to better understand the thermal properties of specimens exactly before the gas adsorption and then foaming process. The related thermal parameters $\left(T_{\mathrm{g}}\right.$ for the glass transition temperature, $T_{\mathrm{cc}}$ and $\Delta H_{\text {cc }}$ for the cold crystallization temperature and its related enthalpy, $T_{\mathrm{m}}$ and $\Delta H_{\mathrm{m}}$ for the melting temperature and related melting enthalpy of PLLA, $T_{\mathrm{sc}-\mathrm{m}}$ and $\Delta H_{\mathrm{sc}-\mathrm{m}}$ for the melting temperature of PLA stereocomplex and related melting enthalpy, $X_{\mathrm{c}}$ for the crystallinity of the PLLA matrix) are recorded in Table $\mathrm{S} 1 \dagger$ for the first and second heating curves, respectively.

The influence of PBAT second phase on the PLLA crystallization behavior is discussed mainly concerning the PBAT concentration. In Fig. 2(a), the cold crystallization temperature slightly decreases to lower temperature with a much smaller cold crystallization enthalpy when the PBAT concentration increases from $10 \mathrm{wt} \%$ to $30 \mathrm{wt} \%$. When PBAT concentration is 

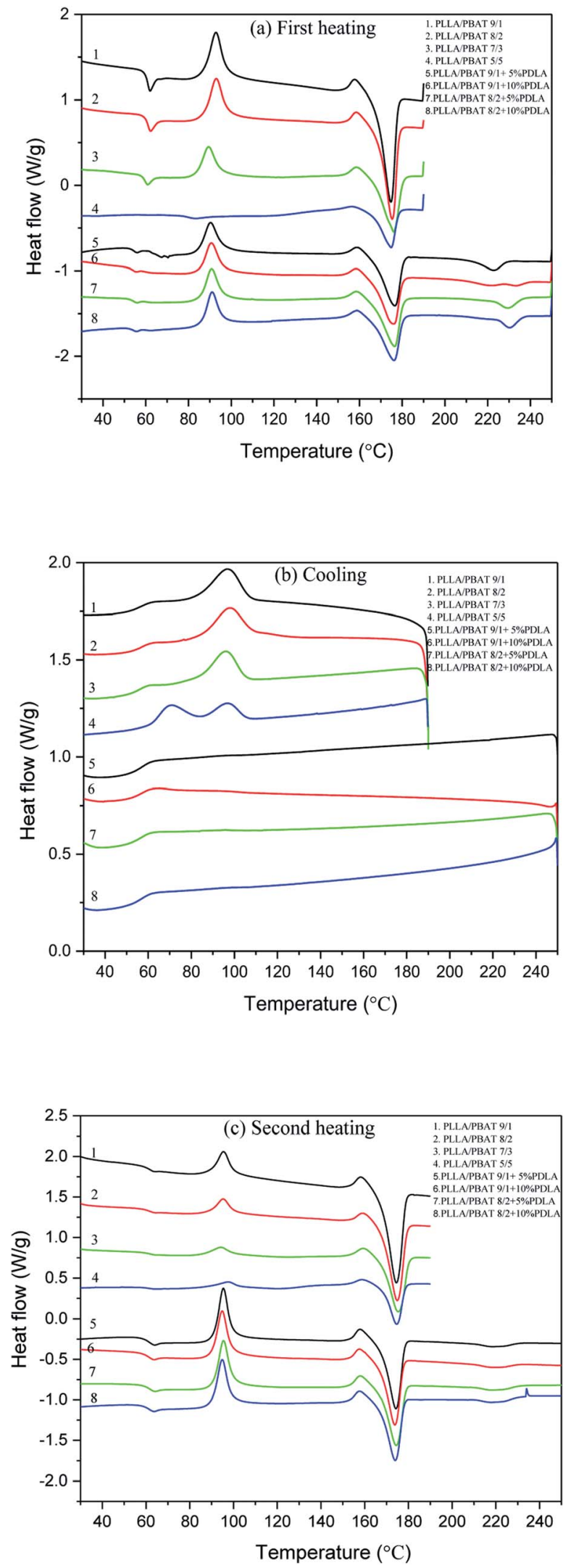

Fig. 2 DSC curves of PLLA/PBAT blends with or without PDLA (a) the first heating curves (b) the cooling curves and (c) the second heating curves. about $50 \mathrm{wt} \%$, there is no cold crystallization peak at all, which means that PLLA already complete its crystallization during the compress molding. Combined with the increasing crystallinity of PLLA/PBAT blends, it can be concluded that PBAT as the incompatible second phase greatly enhancing the PLLA crystallization behavior with accelerated crystallization rate and increased crystallinity. This is consistent with the study of biodegrade PLA/PBAT blends in literature. ${ }^{26}$ Another interesting phenomenon is the presence of a small exothermal $\left(P_{\mathrm{ex}}\right)$ prior to the dominated melting peak in the heating curves, which is corresponding to the transition of $\alpha^{\prime}$-form crystals to their $\alpha$ counterparts. The $\alpha^{\prime}$-form crystals differ from the $\alpha$-form with a looser and disordered molecular packing within the unit cell, corresponding to the larger lattice dimension and weaker interchain interaction. In our work, the present of the $\alpha^{\prime}-$ $\alpha$ transition could be related to the quench process from the compounding temperature of $185{ }^{\circ} \mathrm{C}$, since the $\alpha^{\prime}$-forms were produced in the crystallization at low crystallization temperature as explained in the literature. ${ }^{\mathbf{4 0 , 4 1}}$

Then the first DSC heating curves of PLLA/PBAT (9/1 or 8/2) with $5 \mathrm{wt} \%$ or $10 \mathrm{wt} \%$ PDLA are discussed mainly concerning the effect of PDLA in the PLLA crystallization behavior. As shown in Fig. 2(a), a typical DSC heating curve of PLLA/PBAT/ PDLA blend shows peaks of $T_{\mathrm{g}}, T_{\mathrm{cc}}, T_{\mathrm{ex}}, T_{\mathrm{m}}$, and $T_{\mathrm{sc}-\mathrm{m}}$. The $T_{\text {sc-m }}$ of PLA stereocomplex is ranged from $220-230{ }^{\circ} \mathrm{C}$, which is about $50{ }^{\circ} \mathrm{C}$ higher than $T_{\mathrm{m}}$ of PLLA homopolymers. The present of $T_{\text {sc-m }}$ confirmed the reserved sc-PLA crystallites in the PLLA/PBAT/PDLA specimens prepared by the compress molding process, and could be evidence for the enhanced rheological characteristics such as complex viscosities and storage modulus. In literature ${ }^{38}$ and our former work, ${ }^{42}$ PDLA could greatly improved the crystallization rate and crystallinity of PLLA homopolymer because of the nucleating effect of scPLA. However, these works are normally investigated on the PLLA/PDLA systems without other polymers.

In order to better investigate the effect of PDLA on the crystallization behavior of PLLA/PBAT blends, both the DSC cooling curves and the second heating curves of binary and ternary blends are further compared and shown in Fig. 2(b) and (c) with the cooling and heating rates of $10{ }^{\circ} \mathrm{C} \mathrm{min}^{-1}$. The related thermal parameters of the second heating curves are reported in Table S1. $\dagger$ The DSC cooling curves show the exothermal crystallization peak at about $98{ }^{\circ} \mathrm{C}$ for the PLLA/ PBAT binary systems, while no crystallization peak at all for the PLLA/PBAT + PDLA ternary systems. Under the cooling rate of $10{ }^{\circ} \mathrm{C} \mathrm{min}{ }^{-1}$, the presence of crystallization peak is evidence of the enhanced crystallization rate, and it is well accepted the pure PLLA has very slow crystallization rate and could crystallize only when the cooling rate is lower than $2{ }^{\circ} \mathrm{C} \mathrm{min}^{-1}$. The DSC cooling process of those samples indicated that the incorporation of PBAT increases the crystallization rate in related to the well separated incompatible domains of PBAT in the PLLA matrix as nucleating agents. While with further addition of PDLA in the PLLA/PBAT blends, the crystallization behavior is greatly prohibited.

The second DSC heating curves shown in Fig. 2(c) again confirmed the effect of PBAT concentration and further 
addition of PDLA on the PLLA systems. With the increasing of PBAT concentration, the cold crystallization peak is less obvious with decreasing enthalpy, in consequences of higher crystallinity of about $30 \%$. However, when PDLA is added in the PLLA/ PBAT systems, the cold crystallization peaks are quite obvious. In other words, single PBAT or PDLA would act as kinds of nucleating agents due to the presence of PBAT domains or formed PLA stereocomplex networks in the PLLA matrix, respectively. While, the addition of both PBAT and PDLA is unfavorable to increase the PLLA crystallinity. This could be explained by the possible sc-PLA network formed in the PLLA/ PBAT blends, which could be the physical cross-linking points to constrain the molecular chain mobility of PLLA when the PDLA amount is $5 \%$ or $10 \%$. In other words, only suitable PDLA concentration would lead to enhanced PLLA crystallization behavior, while too much amount of PDLA and then sc-PLA networks would constrain the PLLA chain mobility.

\section{Effect of PDLA on the dynamic mechanical properties of PLLA/ PBAT blends}

DMA was used to study the viscoelastic properties of the PLLA/ PBAT blend with or without PDLA at temperatures lower than the glass transition temperature. In Fig. 3(a), the storage modulus curves of PLLA/PBAT blend and the PLLA/PBAT/PDLA ternary blends are displayed. All the storage modulus curves first keep plateau and then started to decrease quickly because of the glass transition, followed by the a slight increase again related to the cold crystallization after $100^{\circ} \mathrm{C}$. The increasing storage moduli at higher temperature is consistent with the above DSC results. In the glassy region, general increased storage moduli can be related to the addition of nanoparticles or the increasing crystallinities. In this work, the storage moduli of PLLA/PBAT binary blends decrease with increase of PBAT amount. For the PLLA/ PBAT blend with the same PBAT concentration, the addition of (5\% or $10 \%$ ) PDLA leads to the decrease of storage moduli. The possible decreased PLLA crystallinity of PLLA/PBAT with PDLA could be the explanation of this result. For example, at $35^{\circ} \mathrm{C}$, the storage modulus of PLLA/PBAT 8/2 is about $2335 \mathrm{MPa}$, while that of PLLA/PBAT $8 / 2+5 \%$ PDLA is about $2150 \mathrm{MPa}$ and that with $10 \%$ PDLA is about $2095 \mathrm{MPa}$.

Fig. 3(b) exhibits the temperature dependence of the $\tan \delta$ curves of PLA, PLLA/PBAT and PLLA/PBAT/PDLA specimens. The transition peak at around $71^{\circ} \mathrm{C}$ of pure PLLA is recognized as dynamic glass transition temperature (dynamic $T_{\mathrm{g}}$ ), which is similar to the reported ones in literature. ${ }^{43}$ With the addition of PBAT and further PDLA, the dynamic glass transition temperature is slightly decreased to lower temperature direction. This can be related to the plasticization effect of the PBAT second phase in the PLLA matrix. Another phenomenon is the decreased area underneath the $\tan \delta$, which represents the damping ability of the materials.

\section{Gas saturation and desorption}

Based on the above investigation of rheological and thermal properties of PLLA/PBAT blends with PDLA, the viscosity of PLLA/PBAT blends can be increased while the PLLA crystallinity
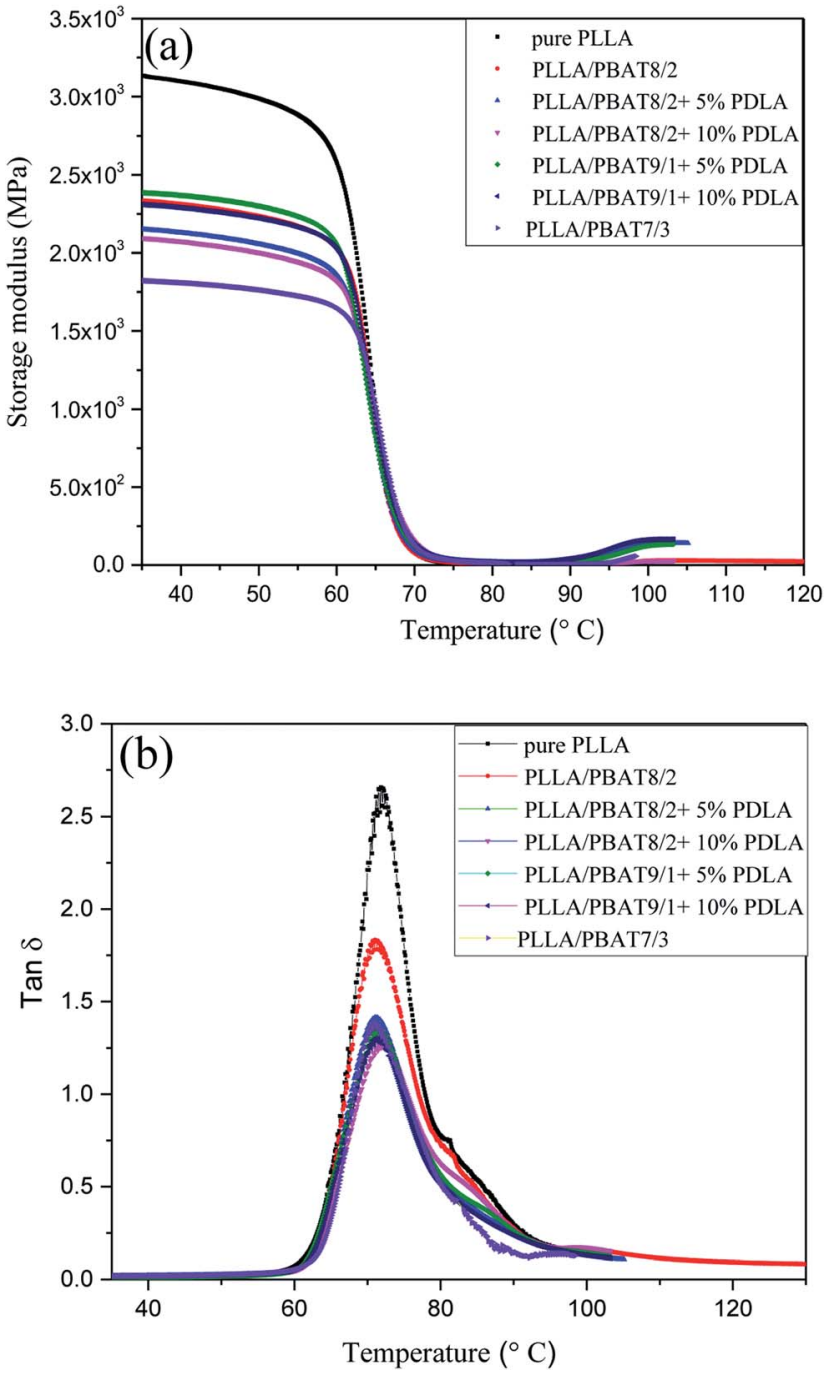

Fig. 3 Temperature dependence of (a) the storage modulus and (b) $\tan \delta$ for PLLA/PBAT blends with or without PDLA.

be decreased, which is strongly related to the PLA stereocomplex crystallites formed between PDLA and PLLA. As expected, enhanced melt strength is favorable for PLLA foaming. Meanwhile, the interesting decreased crystallinity is also favorable for the gas absorption and then for the cell morphology.

Therefore, the gas adsorption and desorption behavior of a series of PLLA/PBAT blends with different amounts of PDLA are further investigated. All the solubility measurement of PLLA and its blends was carried out when the saturation condition was under a pressure of $15 \mathrm{MPa}$ at $40^{\circ} \mathrm{C}$. As shown in Fig. 4, the $\mathrm{scCO}_{2}$ has a higher solubility in the PLLA matrix due to the good affinity between $\mathrm{scCO}_{2}$ and PLLA, which is about $22.6 \mathrm{~g} \mathrm{CO}_{2} /$ $100 \mathrm{~g}$ polymer, much higher than that of the introduced PBAT second phase as shown in Table $\mathrm{S} 2 \dagger\left(8.95 \mathrm{~g} \mathrm{CO}_{2} / 100 \mathrm{~g}\right.$ polymer, $\left.15 \mathrm{MPa}, 40^{\circ} \mathrm{C}\right)$, PA66 $\left(1.3 \mathrm{~g} \mathrm{CO}_{2} / 100 \mathrm{~g}\right.$ polymer, $\left.13.8 \mathrm{MPa}, 40^{\circ} \mathrm{C}\right)$, $\mathrm{PP}\left(0.1 \mathrm{~g} \mathrm{CO}_{2} / 100 \mathrm{~g} \text { polymer, } 13.8 \mathrm{MPa}, 40^{\circ} \mathrm{C}\right)^{44}$ and $\mathrm{PC}\left(9 \mathrm{~g} \mathrm{CO}_{2} /\right.$ $100 \mathrm{~g}$ polymer, $\left.12 \mathrm{MPa}, 60{ }^{\circ} \mathrm{C}\right) .{ }^{45}$

Due to the second PBAT with a weaker interaction with carbon dioxide, therefore lower gas solubility of $\mathrm{CO}_{2}$ in PBAT 


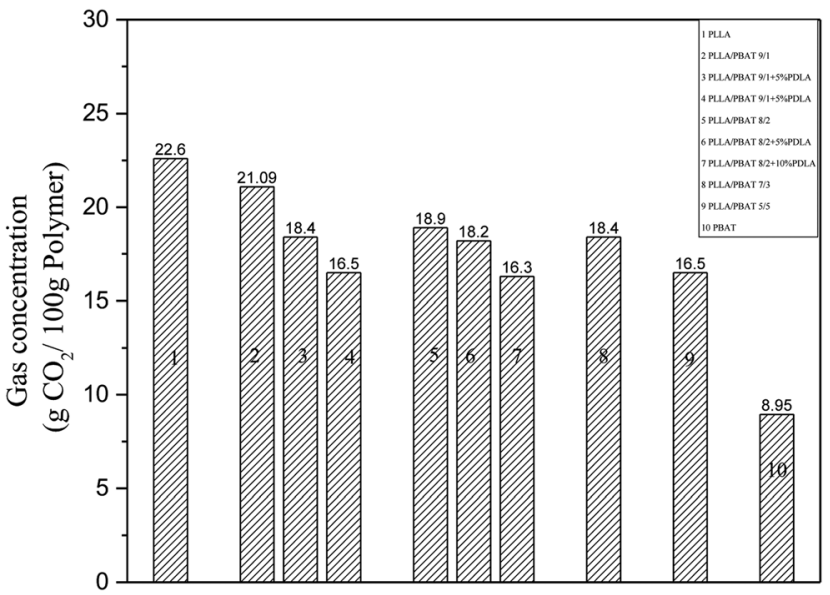

Fig. 4 Solubility of $\mathrm{CO}_{2}$ in PLLA/PBAT-based blends at $15 \mathrm{MPa}$ and at $45^{\circ} \mathrm{C}$.

can be one reason for the decreased gas solubilities of PLLA/ PBAT binary blends. However, the reported values in Fig. 4 did not match the calculated value based on consideration of weight fraction in Table $\mathrm{S} 2 \dagger$ (weight fraction of PLLA $\times$ gas solubility in pure PLLA $+(1-$ weight fraction of PLLA $) \times$ gas solubility in pure PBAT). For PLLA/PBAT 9/1, the real gas solubility of carbon dioxide is about $21.09 \mathrm{~g} \mathrm{CO}_{2} / 100 \mathrm{~g}$ polymer, which is lower than the calculated gas solubility of about $21.24 \mathrm{~g}$ $\mathrm{CO}_{2} / 100 \mathrm{~g}$ polymer. Basically, there are another two main parameters related to the gas adsorption for the polymer immiscible blends. One is the micromorphology of polymer blends, especially the created interfacial zones considered as the gas reservoir, which is favorable for the gas solubility of carbon dioxide. The other parameter to concern about the gas solubility in polymer is the change of PLLA crystallinity. It is well known that high crystallinity is also unfavorable for the gas adsorption due to the very well-organized chain-mold crystalline structure. Zhai et al. ${ }^{13}$ also reported the crystal domains cannot absorb gas but it works as the inert fillers to supply new cell nucleation sites. In other words, the $\mathrm{CO}_{2}$ trapped in the interfacial section could not compensate the solubility loss in related to the increased crystallinity.

Furthermore, for the PLLA blend with the same amount of PBAT, the incorporation of PDLA will lead to a decrease of total carbon dioxide solubility as shown in Fig. 4. Combined with the above discussion on the PLA stereocomplexation between PDLA and the PLLA matrix, the formed sc-PLA crystallite or the existed physical crosslink points in the PLLA matrix are not favorable for the $\mathrm{CO}_{2}$ solubility. In literature, some research reported the decreased solubility of carbon dioxide in the polymer with the addition of clay or glass fibers. ${ }^{46-48}$ The PLLA/PBAT/PDLA ternary blend can be beneficial for the gas absorption in the PLLA matrix and then for the foaming process. Meanwhile, the sc-PLA crystals would act as cell nucleating sites to enhance the cell nucleation.

Since both nucleation and cell growth mechanisms are affected by the amount of gas dissolved in the material (gas concentration) and the rate of gas diffusion (diffusivity), it is important to investigate the gas saturation and desorption behaviors in the solid-state batch foaming process. Fig. 5 presents the desorption curves of studied PLLA binary or ternary blends just after the fully saturation. All the samples show similar gas desorption tendency, which keeps decreasing with time. For PLLA/PBAT blend, with more PBAT, the lower gas concentration in the blend after the same desorption time. Another thing we have to declare is that for the PLLA/PBAT/ PDLA ternary systems, the addition of PDLA and therefore the presence of sc-PLA crystallites in the systems present a slightly higher gas concentration when the desorption time is longer than 30 min. Both for PLLA/PBAT 8/2 and PLLA/PBAT 9/1, either $5 \%$ PDLA or $10 \%$ PDLA will result in a higher gas amount. In other words, the formed sc-PLA crosslink-points in the matrix prohibit the gas desorption and in consequence of a lower gas desorption rate. Combined with the gas adsorption results, the existed sc-PLA crystallites is unfavorable for both gas adsorption and desorption, which is related to the special strong intermolecular hydrogen interaction between PLLA and PDLA.

\section{Phase morphology and cell morphology of PLLA/PBAT and PLLA/PBAT/PDLA blends}

Fig. 6(a)-(h) show the morphology of the fracture surfaces for PLLA/PBAT with different PBAT amounts and Fig. 6(i) and (j) for PLLA/PBAT/PDLA blends with 10\% PDLA, after foaming at a lower temperature of $120{ }^{\circ} \mathrm{C}$ in order to achieve partially foaming while keeping both the PLA and PBAT phase distinguished. Consistent with the above DMA results, the PLLA/PBAT blends are immiscible system. The PBAT second phase in the PLLA matrix separates well uniformly as domains when the concentration is only $10 \mathrm{wt} \%$. With the increase of PBAT concentrations, the size of the well separated white domains in the PLLA matrix increases. Even when the PBAT phase is $40 \%$ or $50 \%$, the second PBAT phase still separates as domains on the investigate surface with bigger size without the presence of cocontinuous phase. As shown in Fig. 6(g), some ductile fracture

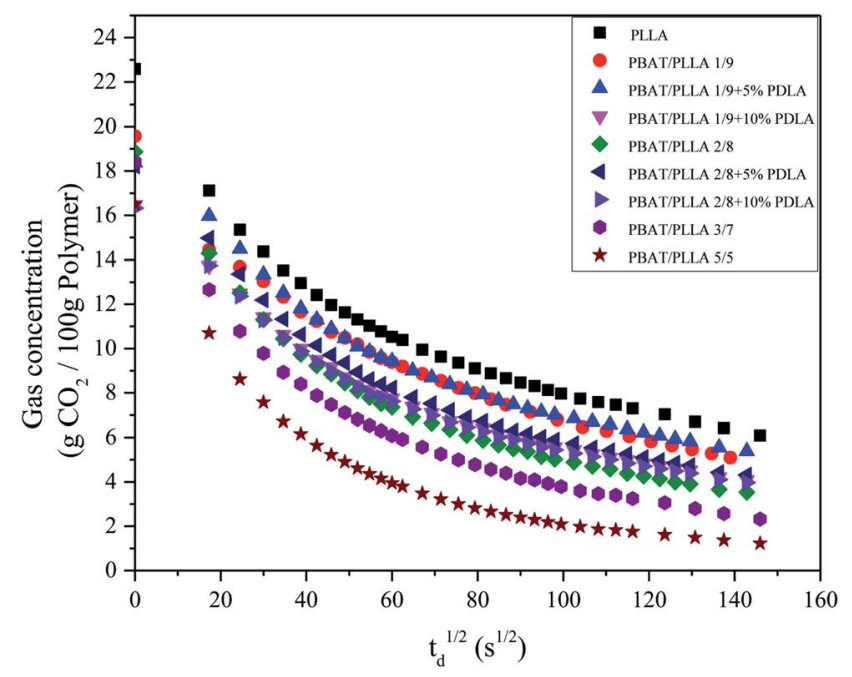

Fig. 5 Plots of measured desorption weight fraction of $\mathrm{CO}_{2}$ in the PLLA/PBAT based blends versus the square root of desorption time. 

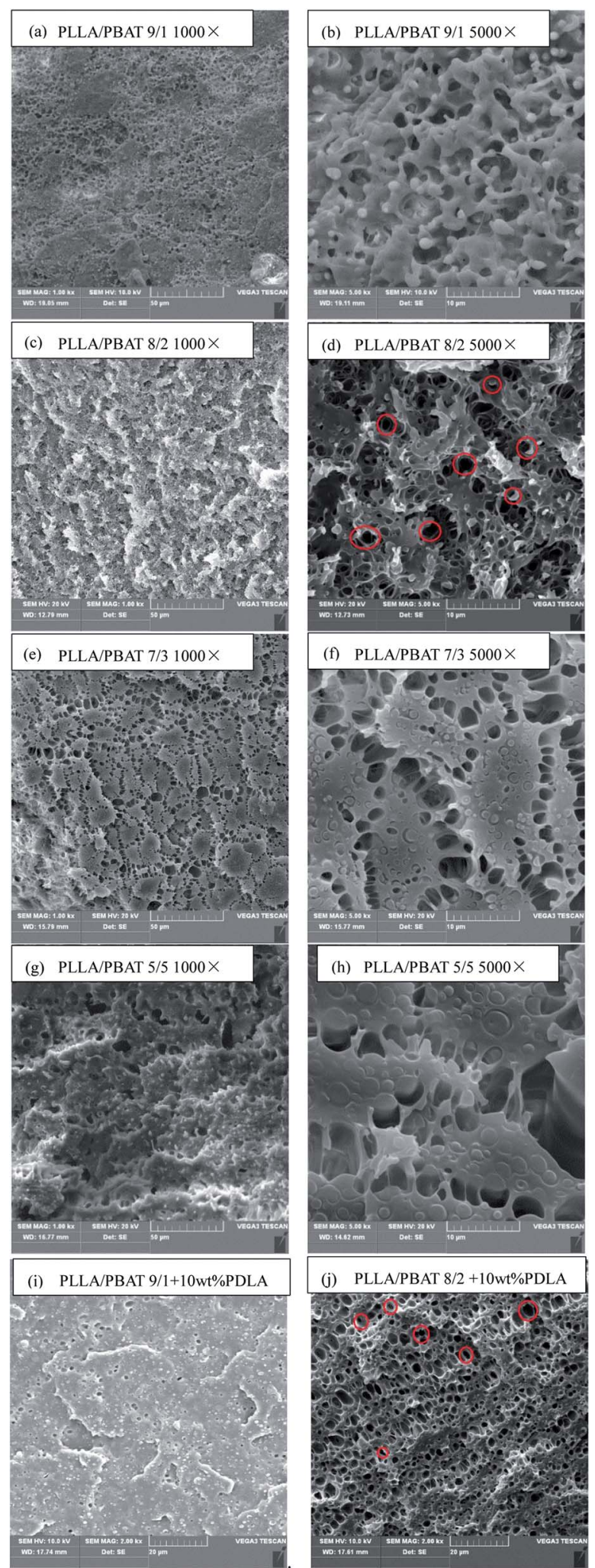

Fig. 6 SEM images for PLLA/PBAT and PLLA/PBAT/PDLA after partially foaming at lower temperature of $120^{\circ} \mathrm{C}$. (a) PLLA/PBAT 9/1 1000x; (b) PLLA/PBAT 9/1 5000x; (c) PLLA/PBAT 8/2 1000x; (d) PLLA/PBAT 8/2 5000x; (e) PLLA/PBAT 7/3 1000x; (f) PLLA/PBAT 7/3 5000x; (g) PLLA/ PBAT 5/5 1000x; (h) PLLA/PBAT 5/5 5000x; (i) PLLA/PBAT 9/1 + 10 wt\% PDLA; (j) PLLA/PBAT 9/1 + 10 wt\% PDLA. surface of PLLA/PBAT 5/5 presents with some pull-out white PBAT fibrils. In other words, the second PBAT phase would exist in the PLLA matrix as the fibers. After those PLLA/PBAT blends foaming partially, it is obvious that the most and first cell nucleation and then growth happen at the interface sites between PLLA and PBAT. With the further incorporation of PDLA in the blends, the morphology is still the twoincompatible morphology as shown in Fig. 6(i) and (j) because of the formed sc-PLA crystals are well compatible with PLLA matrix and there is no big different for the size of separated PBAT droplets.

Following the same foaming conditions, PLLA/PBAT 8/2 blend either with or without PDLA presents the most good foaming behavior. As it can be seen from Fig. 6(d), some PBAT droplets marked in red are crescent shape, with some cavities around. We can say this SEM image as a middle stage during the foaming just after the cell nucleating but not fully growth. In addition, some black holes or open cells marked in red can be observed in Fig. 6(j). As well known, the typical cell morphology of pure PLLA is close-cell structure and it is still a big challenge to prepare PLLA with open cell structure without the collapse of all foams. In this work, even at partially foaming temperature, PBAT phase is already in a soft state due to its lower melting temperature of about $120{ }^{\circ} \mathrm{C}$. Both the gas absorbed and cell nucleated mostly happens in the interfacial sites in related to the bad compatibility. Then cell growth prefers to orient to the soft PBAT phase and until push the PBAT shaped like crescent shape or stretched fiber until the open cells become stable. That is the basic foaming mechanism of the PLLA/PBAT binary blends. Some similar results have been reported in literature for PLA/PBS systems. ${ }^{24}$

The cell morphologies of PLLA/PBAT-based blends are further investigated in this work via batch foaming processing. In this work, a temperature rising process (at $150{ }^{\circ} \mathrm{C}$ for $15 \mathrm{~s}$ ) was carried out to foam the gas saturated PLLA/PBAT blends (at $15 \mathrm{MPa}$ for 8 hours) with or without PDLA. Fig. 7 shows the cell morphology of PLLA/PBAT 9/1 blends with different PDLA contents. Compared to the morphology of PLLA/PBAT 9/1 system, the incorporation of PDLA leads to the decrease of average cell size and increase of the cell density. It seems that PLLA/PBAT 9/1 and PLLA/PBAT 9/1 + 1\% PDLA foams have uniform cell structure and similar cell morphology. The related average cell size is about 2.59 and $1.92 \mu \mathrm{m}$, respectively. A further increase of PDLA amount in the system seems to affect the cell morphology of relates blends significantly. For PLLA/ PBAT 9/1 + 5\% PDLA, the cell size decreases as shown in Fig. 7(e), with its the SEM image at higher magnification of $5000 \times$ as shown in Fig. 7(f). The cell size is too tiny to do the statistics calculation. In addition, the fracture surface presents kind of ductile fracture characteristics. Those results indicate that the introduction of PDLA and then the sc-PLA stereocomplex crystals facility the decrease of cell average size. In other words, the formed sc-PLA stereocomplex can also act as cell nucleating sites.

Fig. 8 shows the cell morphology of PLLA/PBAT 8/2-based blends and their related cell distribution. Firstly, the addition of $20 \mathrm{wt} \%$ PBAT (Fig. 8(a)) slight increases the cell average size compared to that of PLLA with $10 \mathrm{wt} \%$ PBAT, mainly due to the 

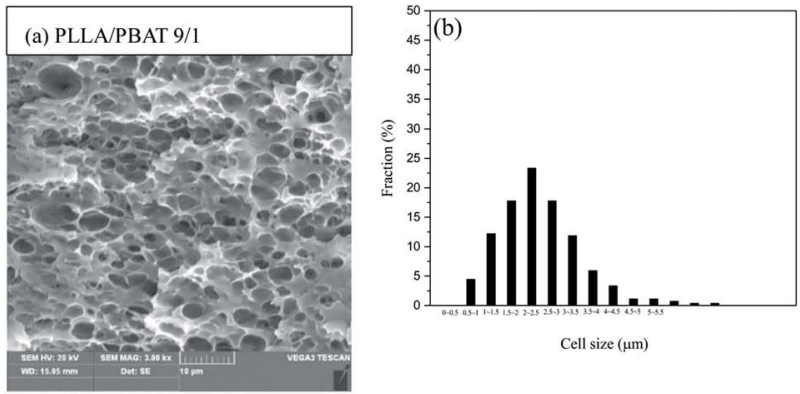

Cell size $(\mu \mathrm{m})$
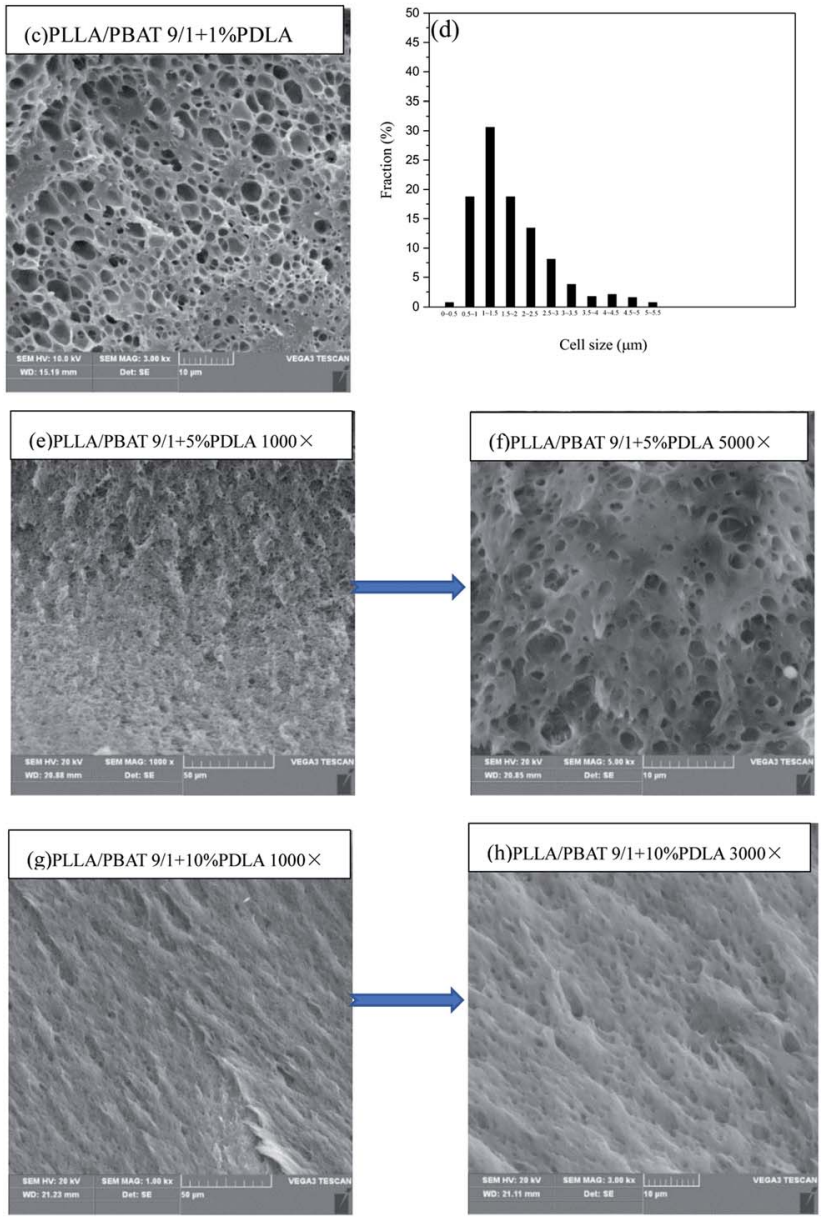

Fig. 7 SEM micrographs of PLLA/PBAT 9/1-based foams with different PDLA and their related cell distribution. (a) and (b) PLLA/PBAT 9/1; (c) and (d) PLLA/PBAT 9/1 + 1 wt\% PDLA; (e) and (f) PLLA/PBAT 9/1 + $5 w t \%$ PDLA with different magnifications; $(g)$ and (h) PLLA/PBAT 9/1 + $10 w t \%$ PDLA with different magnifications.

increasing size of PBAT domains in the PLLA matrix and meanwhile the slight decrease of gas saturation solubility discussed above. With the introduction of $1 \mathrm{wt} \%, 5 \mathrm{wt} \%$ and then $10 \mathrm{wt} \%$ PDLA in the PLLA/PBAT 8/2 system, the corresponding SEM images are shown in Fig. 8(c), (e) and (g), respectively. All those SEM images show obvious open-cell structures, which indicate the sc-PLA crystallites in the system basically have no effect on the micro-morphological structure of PBAT. Similar with the tendency shown in Fig. 8, the addition of PDLA leads to the decreasing of cell average size and increasing of the cell density. The cell distributions as shown in Fig. 8(b), (d) and (e)
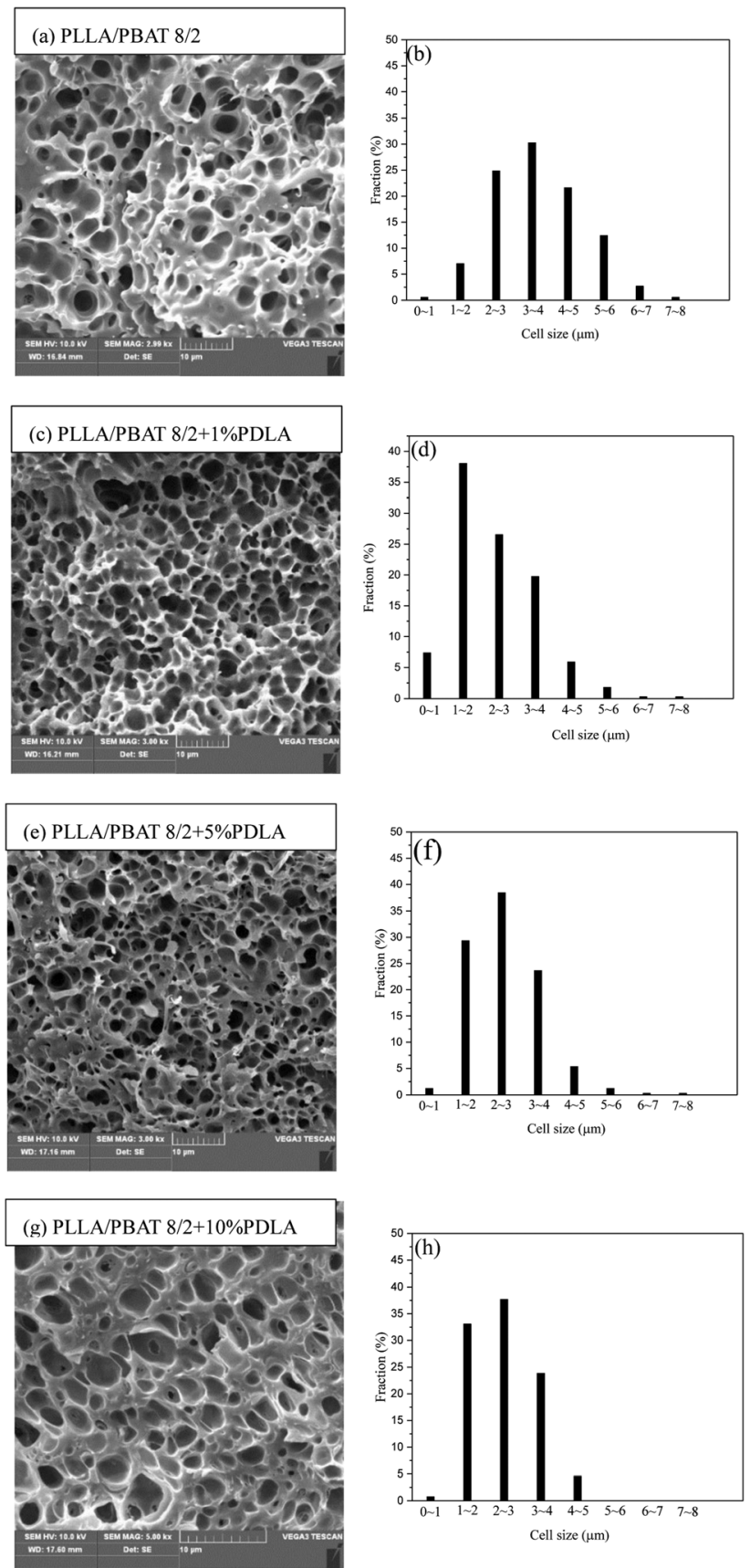

Fig. 8 SEM micrographs of PLLA/PBAT 8/2-based foams with different PDLA and their related cell distribution. (a) and (b) PLLA/PBAT 8/2; (c) and (d) PLLA/PBAT 8/2 + 1 wt\% PDLA; (e) and (f) PLLA/PBAT 8/2 +5 wt $\%$ PDLA; $(g)$ and (h) PLLA/PBAT $8 / 2+10$ wt $\%$ PDLA.

present a shift to the lower cell size. For example, the average cell sizes for Fig. 8(c) and (e) are 2.37 and $2.25 \mu \mathrm{m}$, respectively. In case of cell density, the relative values are $2.51 \times 10^{10}$ and $2.91 \times 10^{10}$ cells per $\mathrm{cm}^{3}$, respectively. This results further verified that the introduction of PDLA in the PLLA/PBAT system accelerate the number of crystals domains, which could not absorb gas and act as the fillers to supply new nucleation sites for the increasing number of cell density. The well cell distribution as shown in Fig. 8(c) and (e) can also confirmed the above the increasing melt strength of the PLLA matrix and 


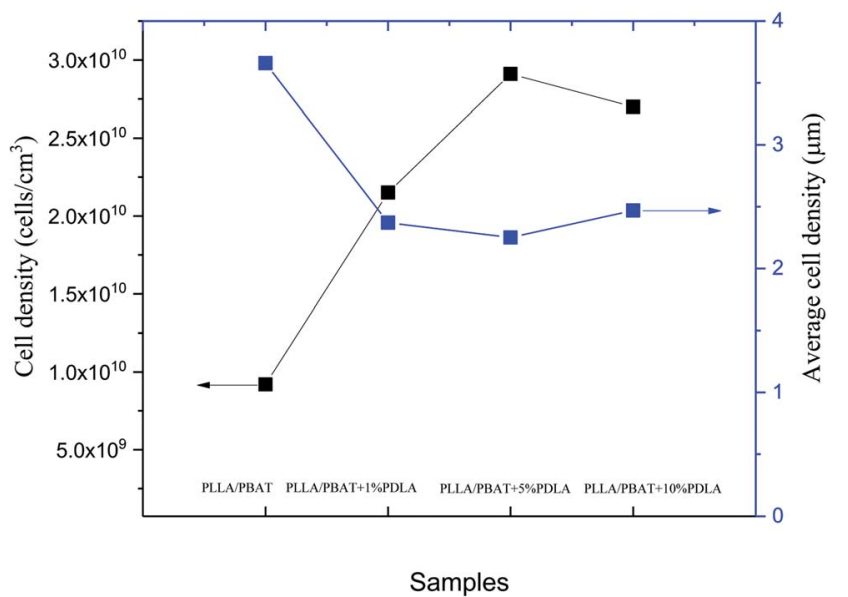

Fig. 9 Average cell size and cell density of PLLA/PBAT foams with different amounts of PDLA.

further provide a strong strain hardening effect for PLLA melt, which is in related to the formation of sc-PLA crystal networks but not the increasing crystallinity.

Fig. 9 show the average cell density and cell density of the selected samples foamed at the same temperature after the same gas saturation process. Combined with Fig. $8(\mathrm{~g})$, the further increase of $10 \mathrm{wt} \%$ PDLA into the PLLA/PBAT 8/2 system results in slightly increase of cell size and decrease of cell density. This result can be explained mainly by the microstructure of reserved sc-PLA crystallites. In our former work, the morphology of Sc-PLA in the PLLA matrix changes with the increasing amounts of PDLA, basically related to the size of the physical crosslinked sites of sc-crystallites. When the PDLA concentration is about $10 \mathrm{wt} \%$, the sc-PLA crystallites linked more densely with the PLLA molecular chains would decrease the chain mobility and therefore lower the crystallization behavior of PLLA, especially the crystallinity of PLLA. In the foaming behavior of PLLA/PBAT 8/2 + 10 wt\% PDLA, the increasing of sc-PLA spherulites and then size of the unfoaming zones will be the explanation of the higher average cell size in Fig. $8(\mathrm{~g})$. The in consequence of lower gas adsorption amount in the ternary systems and therefore less nucleating sites can be considered as another potential reason. A suitable PDLA will be favorable for melt strength and then foaming process, while much higher PDLA and in consequence of more sc-PLA crystallites would lead to the constrained molecular chain mobility and large size of sc-PLA crystals, which is unfavorable for PLA foaming process.

\section{Conclusion}

In this work, the PLLA/PBAT system was melt blended with different PDLA, and the influence of PLA stereocomplex crystallite (sc-PLA) with high melting temperature and thermal stability on the rheological, crystallization and dynamical mechanical properties of PLLA are investigated. Furthermore, the batch foaming behavior of PLLA/PBAT system with or without PDLA was discussed based on the gas absorption of supercritical carbon dioxide and the above thermal properties. The introduction of PDLA and then the sc-PLA crystallites promoted the rheological properties, especially the complex viscosity of PLLA/PBAT system efficiently, which is due to the reserved sc-PLA crystals acted as crosslinking sites. The most interesting result is that the crystallization behavior for PLLA/PBAT with PDLAs can be the decreased crystallinity and also the crystallization rate. With the addition of only PBAT, the crystallization behavior of the PLLA matrix was greatly enhanced. While with further addition of $5 \mathrm{wt} \%$ or $10 \mathrm{wt} \%$ PDLA in the PLLA/PBAT system, the crystallinity was decreased. This difference from the nucleating effect of Sc-PLA for the pure PLLA in literature can be in related to the constrained PLLA molecular chain mobility own to the PDLA amounts. In addition, the constrained effect was so strong to blanket the nucleating effect of PBAT in the ternary blend.

The enhanced rheological viscosities of PLLA/PBAT with PDLA and meanwhile the decreasing crystallinity of the PLLA matrix were favorable for the foaming process and gas absorption process, respectively. The cell morphology of PLLA/PBAT binary foams are found in open-cell structure instead of typical close-cell structure for pure PLLA. The introduction of the second soft immiscible PBAT is the dominating factor for the open-cells structure of PLA foams due to the cell growth towards to the PBAT phase. The cell growth process was simulated by a middle stage foaming at lower temperature. The resultant PLLA/PBAT/PDLA foam exhibited a significant and concurrent decrease of the average cell size and increase of cell density with better cell distribution, relative to the PLLA/PBAT foam. The reserved sc-PLA crystallites acted as the cell nucleating agents and therefore the decreasing cell size, promoting the PLLA foaming behavior without cell coalescence.

\section{Conflicts of interest}

There are no conflicts to declare.

\section{Acknowledgements}

The authors would like to acknowledge the financial support of the National Natural Science Foundation of China (No. 51773170 and No. 51303149), the Natural Science Foundation of Shaanxi Province in China (No. 2015JQ2045).

\section{References}

1 K. M. Nampoothiri, N. R. Nair and R. P. John, An overview of the recent developments in polylactide (PLA) research, Bioresour. Technol., 2010, 101, 8493-8501.

2 L. T. Lim, R. Auras and M. Rubino, Processing technologies for poly(lactic acid), Prog. Polym. Sci., 2008, 33, 820-852.

3 I. Armentano, N. Bitinis, E. Fortunati, S. Mattioli, N. Rescignano, R. Verdejo, M. A. Lopez-Manchado and J. M. Kenny, Multifunctional nanostructured PLA materials for packaging and tissue engineering, Prog. Polym. Sci., 2013, 38, 1720-1747.

4 A. Gandini, Polymers from renewable resources: a challenge for the future of macromolecular materials, Macromolecules, 2008, 41, 9491-9504. 
5 F. Tasaka, Y. Ohya and T. Ouchi, One-pot synthesis of novel branched polylactide through the copolymerization of lactide with mevalolactone, Macromol. Rapid Commun., 2001, 22, 820-824.

6 K. Zhang, A. K. Mohanty and M. Misra, Fully biodegradable and biorenewable ternary blends from polylactide, poly(3hydroxybutyrate-co-hydroxyvalerate) and poly(butylene succinate) with balanced properties, ACS Appl. Mater. Interfaces, 2012, 4, 3091-3101.

7 Z. X. Jing, X. T. Shi, G. C. Zhang and R. Y. Lei, Investigation of poly(lactide) stereocomplexation between linear poly(Llactide) and PDLA-PEG-PDLA tri-block copolymer, Polym. Int., 2015, 64, 1399-1407.

8 Z. Kulinski, E. Piorkowska, K. Gadzinowska and M. Stasiak, Plasticization of Poly(L-lactide) with Poly(propylene glycol), Biomacromolecules, 2006, 7, 2128-2135.

9 X. Shi, G. Zhang, C. Siligardi, G. Ori and A. Lazzeri, Comparison of precipitated calcium carbonate/polylactic acid and halloysite/polylactic acid nanocomposites, $J$. Nanomater., 2015, 1, 67.

10 M. Nofar and C. B. Park, Poly (lactic acid) foaming, Prog. Polym. Sci., 2014, 39, 1721-1741.

11 L. Q. Xu and H. X. Huang, Foaming of poly(lactic acid) using supercritical carbon dioxide as foaming agent: influence of crystallinity and spherulite size on cell structure and expansion ratio, Ind. Eng. Chem. Res., 2014, 53, 2277-2286.

12 Y. Di, S. Iannace, E. D. Maio and L. Nicolais, Reactively modified poly(lactic acid): properties and foam processing, Macromol. Mater. Eng., 2005, 290, 1083-1090.

13 P. Jia, W. Zhai, Y. Duan, J. Zhang and C. Han, Cell morphology and improved heat resistance of microcellular poly(l-lactide) foam via introducing stereocomplex crystallites of PLA, Ind. Eng. Chem. Res., 2015, 54, 2476-2488.

14 Y. M. Corre, A. Maazouz, J. Duchet and J. Reignier, Batch foaming of chain extended PLA with supercritical $\mathrm{CO}_{2}$ : Influence of the rheological properties and the process parameters on the cellular structure, J. Supercrit. Fluids, 2011, 58, 177-188.

15 J. M. Julien, J. C. Quantin, J. C. Benezet, A. Bergeret, M. F. Lacrampe and P. Krawczaka, Chemical foaming extrusion of poly(lactic acid) with chain-extenders: Physical and morphological characterizations, Eur. Polym. J., 2015, 67, 40-49.

16 J. Dorgan, J. Janzen, M. Clayton, S. B. Hait and D. M. Knauss, Melt rheology of variable L-content poly(lactic acid), J. Rheol., 2005, 45, 607-619.

17 L. Palade, H. Lehermeier and J. Dorgan, Melt rheology of high L-content poly(lactic acid), Macromolecules, 2001, 34, 1384-1390.

18 G. Ji, W. Zhai, D. Lin, Q. Ren, W. Zheng and D. Jung, Microcellular foaming of PLA/Silica nanocomposites in compressed $\mathrm{CO}_{2}$ : critical influence of crystallite size on cell morphology and foam expansion, Ind. Eng. Chem. Res., 2013, 52, 6390-6398.

19 M. Keshtkar, M. Nofar, C. B. Park and P. J. Carreau, Extruded PLA/clay nanocomposite foams blown with supercritical $\mathrm{CO}_{2}$, Polymer, 2014, 55, 4077-4090.
20 M. Mihai, M. A. Huneault, B. D. Favis and H. Li, Extrusion foaming of semi-crystalline PLA and PLA/thermoplastic starch blends, Macromol. Biosci., 2007, 7, 907-920.

21 W. Zhai, K. Yoorim, W. Zhu, W. Anson and C. B. Park, A study of the crystallization, melting, and foaming behaviors of polylactic acid in compressed $\mathrm{CO}_{2}$, Int. J. Mol. Sci., 2009, 10, 5381-5397.

22 H. B. Zhao, Z. X. Cui, X. F. Wang, L.-S. Turng and X. F. Peng, Processing and characterization of solid and microcellular poly(lactic acid)/polyhydroxybutyrate-valerate (PLA/PHBV) blends and PLA/PHBV/clay nanocomposites, Composites, Part B, 2013, 51, 79-91.

23 S. Pilla, S. Kim, G. K. Auer, S. Gong and C. B. Park, Microcellular extrusion foaming of poly(lactide)/poly(butylene adipate-coterephthalate) blends, Mater. Sci. Eng., C, 2010, 30, 255-262.

24 P. Yu, H. Y. Mi, A. Huang, et al., Effect of poly(butylenes succinate) on poly(lactic acid) foaming behavior: formation of open cell structure, Ind. Eng. Chem. Res., 2015, 54, 61996207.

25 X. Shi, G. Zhang, Y. Liu, Z. Ma, Z. Jing and X. Fan, Microcellular foaming of polylactide and poly(butylene adipate-co-terphathalate) blends and their $\mathrm{CaCO}_{3}$ reinforced nanocomposites using supercritical carbon dioxide, Polym. Adv. Technol., 2016, 27, 550-560.

26 L. Jiang, M. P. Wolcott and J. Zhang, Study of biodegradable polylactide/poly(butylene adipate-co-terephthalate) blends, Biomacromolecules, 2006, 7, 199-207.

27 M. Nofar, A. Tabatabaei, H. Sojoudiasli, C. B. Park, P. J. Carreau, M.-C. Heuzey and M. R. Kamal, Mechanical and bead foaming behavior of PLA-PBAT and PLA-PBSA blends with different morphologies, Eur. Polym. J., 2017, 90, 231-244.

28 S. Li, G. He, X. Liao, C. B. Park, Q. Yang and G. Li, Introduction of a long-chain branching structure by ultraviolet-induced reactive extrusion to improve cell morphology and processing properties of polylactide foam, RSC Adv., 2017, 7, 6266-6277.

29 S. Bourbigot, G. Fontaine, S. Bellayer and R. Delobel, Processing and nanodispersion: a quantitative approach for polylactide nanocomposites, Polym. Test., 2008, 27, 2-10.

30 E. M. Woo and L. Chang, Crystallization and morphology of stereocomplexes in nonequimolar mixtures of poly (L-lactic acid) with excess poly (D-lactic acid), Polymer, 2011, 52, 6080-6089.

$31 \mathrm{H}$. Yamane and K. Sasai, Effect of the addition of poly(d-lactic acid) on the thermal property of poly(l-lactic acid), Polymer, 2003, 44, 2569-2575.

32 S. Nouri, C. Dubois and P. G. Lafleur, Effect of chemical and physical branching on rheological behavior of polylactide, $J$. Rheol., 2015, 59, 1045-1063.

33 E. W. Fischer, H. J. Sterzel and G. Wegner, Investigation of the structure of solution grown crystals of lactide copolymers by means of chemical reactions, Colloid Polym. Sci., 1973, 251, 980-990.

34 A. Wong and C. B. Park, The effects of extensional stresses on the foamability of polystyrene-talc composites blown with carbon dioxide, Chem. Eng. Sci., 2012, 75, 49-62. 
35 Z. Jing, X. Shi, G. Zhang, J. Li, J. Li, L. Zhou and H. Zhang, Formation, structure and promoting crystallization capacity of stereocomplex crystallite network in the poly(lactide) blends based on linear PLLA and PDLA with different structures, Polymer, 2016, 92, 210-211.

36 F. Du, R. C. Scogna, W. Zhou, S. Brand, J. E. Fischer and K. I. Winey, Nanotube Networks in Polymer Nanocomposites: Rheology and Electrical Conductivity, Macromolecules, 2004, 37, 9048-9055.

37 T. Kashiwagi, F. Du, J. F. Douglas, K. I. Winey, R. H. Harris Jr and J. R. Shields, Nanoparticle networks reduce the flammability of polymer nanocomposites, Nat. Mater., 2005, 4, 928-933.

38 L. Aliotta, P. Cinelli, M. B. Coltelli, M. C. Righetti, M. Gazzano and A. Lazzeri, Effect of nucleating agents on crystallinity and properties of poly (lactic acid) (PLA), Eur. Polym. J., 2017, 93, 822-832.

39 N. Rahman, T. Kawai, G. Matsuba, K. Nishida, T. Kanaya, H. Watanabe, H. Okamoto, M. Kato, A. Usuki, M. Matsuda, K. Nakajima and N. Honma, Effect of Polylactide Stereocomplex on the Crystallization Behavior of Poly(1lactic acid), Macromolecules, 2009, 42, 4739-4745.

40 J. Zhang, K. Tashiro, H. Tsuji and A. J. Domb, Disorder-toOrder Phase Transition and Multiple Melting Behavior of Poly(l-lactide) Investigated by Simultaneous Measurements of WAXD and DSC, Macromolecules, 2008, 41, 1352.

41 M. Yasuniw, K. Sakamo, Y. Ono and W. Kawahara, Melting behavior of poly(-lactic acid): X-ray and DSC analyses of the melting process, Polymer, 2008, 49, 1943-1951.
$42 \mathrm{X}$. Shi, G. Zhang, T. Phuong and A. Lazzeri, Synergistic effects of nucleating agents and plasticizers on the crystallization behavior of poly(lactic acid), Molecules, 2015, 20, 1579-1593.

43 J. T. Yeh, C. H. Tsou, C. Y. Huang, K. N. Chen, C. S. Wu and W. L. Chai, Compatible and crystallization properties of poly(lactic acid)/poly(butylene adipate-co-terephthalate) blends, J. Appl. Polym. Sci., 2010, 116, 680-687.

44 D. L. Tomasko, H. B. Li, D. H. Liu, X. M. Han, M. J. Wingert, L. J. Lee and K. W. Koelling, A Review of $\mathrm{CO}_{2}$ Applications in the Processing of Polymers, Ind. Eng. Chem. Res., 2003, 42, 6431-6456.

45 Z. Ma, G. Zhang, Q. Yang, X. Shi and A. Shi, Fabrication of microcellular polycarbonate foams with unimodal or bimodal cell-size distributions using supercritical carbon dioxide as a blowing agent, J. Cell. Plast., 2014, 50, 55-79.

46 M. M. Hasan, A systematic study of solubility of physical blowing agents and their blends in polymers and their nanocomposites, Ph.D. thesis, University of Toronto, 2013.

47 M. Keshtkar, M. Nofar, C. B. Park and P. J. Carreau, Extruded PLA/clay nanocomposite foams blown with supercritical $\mathrm{CO}_{2}$, Polymer, 2014, 55, 4077-4099.

48 Z. Ma, G. Zhang, Q. Yang, X. Shi, J. Li and X. Fan, Microcellular foams of glass-fiber reinforced poly (phenylene sulfide) composites generated using supercritical carbon dioxide, Polym. Compos., 2015, 37, 2527-2540. 